\title{
Impacto de la población extranjera en la evolución y la estructura por edad de la población del municipio de Málaga
}

\author{
Juan José NATERA Rivas \\ Departamento de Geografía. Universidad de Málaga \\ jjnatera@uma.es \\ Ana Ester BATISTA ZAMORA \\ Departamento de Geografía. Universidad de Málaga \\ anabatista@uma.es
}

Recibido: 23 de octubre de 2011

Enviado a evaluar: 4 de febrero de 2012

Aceptado: 24 de abril de 2012

\section{RESUMEN}

La población extranjera empadronada en el municipio de Málaga ha experimentado un importante aumento hasta alcanzar el $8,27 \%$ en 2010 , y a ella se debe la práctica totalidad del aumento de población que el municipio ha experimentado desde 2003. Los foráneos no se distribuyen de manera homogénea en el tejido urbano malagueño y, en este contexto, el objetivo del presente trabajo es indagar acerca de la influencia que la llegada de estos contingentes ha tenido sobre la población residente en 2003 en dos aspectos: el primero de ellos, sobre el comportamiento de los volúmenes totales de población; el segundo, sobre la estructura por edad de la población preexistente. La información que hemos empleado proviene de los registros padronales correspondientes a los años 2003 y 2010, obtenidos del Ayuntamiento de Málaga, y el nivel de desagregación espacial seleccionado es el barrio.

Palabras clave: Población extranjera, estructura por edad, Málaga.

\section{Impact of Foreign Population on the Evolution and Age Structure of the Population of the Municipality of Malaga}

\begin{abstract}
The foreign population registered in the municipality of Malaga has experienced an important increase, reaching $8,27 \%$ in 2010 , and on it's growth lies the reason of the bulk of the increase that the population of the municipality has experienced since 2003. Foreigners are not distributed in a homogeneous way in the urban tissue and, in this context, the aim of this paper is to investigate the influence that the arrival of these population has had on the resident population in 2003 in two aspects: the first one, on the behaviour of the total volume of population; the second one, on the age structure of the pre-existing population. The information that we have used comes from the "padrones" corresponding to the year 2003 and 2010, obtained from the Municipality of Malaga, and the spatial unit we have used is the neighbourhood.
\end{abstract}

Key words: Foreing population, Age Structure, Malaga. 
Impact de la population étrangère dans l'évolution et la structure par âge de la population de la municipalité de Málaga

\section{RÉSUMÉ}

La population étrangère recensée dans la municipalité de Malaga a expérimenté une augmentation importante jusqu'à atteindre $8,27 \%$ en 2010 , et on doit à elle la totalité pratique de l'augmentation de la population que la municipalité a expérimentée dès 2003. Cette population n'est pas distribuée d'une manière homogène dans le tissu urbain malaguène et, dans ce contexte, l'objectif du travail présent est de rechercher à propos de l'influence que l'arrivée de ces contingents a eue sur la population résidante en 2003 dans deux aspects: le premier d'eux, sur le comportement des volumes totaux de population; le deuxième, sur la structure par âge de la population pré-existante. L'information que nous avons employée provient des registres padronales correspondants aux années 2003 et 2010, obtenues du Conseil municipal de Malaga, et le niveau de désagrégation spatiale sélectionné est le quartier.

Mots-clés: Population étrangère, structure par âge, Málaga.

\section{INTRODUCCIÓN}

La influencia de la población extranjera sobre los contingentes de población es un tema tratado con cierta frecuencia en diferentes niveles de resolución espacial (Haffar y Heredia, 2005; López e Izquierdo, 2005; Gil, 2008; Bayona y Gil, 2010; Roquer y Blay, 2010;), al tiempo que su influencia sobre la estructura por edad de la población también ha sido considerada por diferentes investigadores (López e Izquierdo, 2003; Carvajal, 2005; González, 2005;). Sin embargo, y siendo esto así, los estudios diacrónicos referidos a estas mismas cuestiones a nivel inframunicipal son menos frecuentes (por ejemplo, Ocaña, 2005b; Bayona, 2008; Bayona y Gil, 2008), un hecho que en nuestra opinión vendría explicado en gran medida por la falta de estabilidad temporal de las unidades espaciales a las que está referida la información de partida, que en la mayor parte de los casos resultan ser las secciones censales; una cuestión sobre la que volveremos en los párrafos siguientes.

En el caso del municipio de Málaga, si bien es cierto que en 2010 los 47.769 foráneos empadronados en el municipio se resolvían como una proporción de la población total comparativamente reducida, el 8,76\%, también lo es el que esta última cifra se ha multiplicado por 10 desde 1998, un incremento que no se ha producido de manera lineal: podría identificarse al periodo 2002/2003 como el momento en el que las incorporaciones de foráneos alcanzaron su máximo, con aportes netos por primera vez por encima de los 6.000 habitantes, que elevaron la tasa de extranjería por encima del 3\%; en contraste, la evolución de los contingentes de la población española ha sido mucho más errática, hasta el punto de que desde 2007 se está registrando un descenso en los mismos.

En este contexto debe enmarcarse el objetivo de la presente investigación, que no es otro que indagar acerca del impacto que ha tenido la llegada de población foránea al municipio de Málaga tanto sobre la evolución de los contingentes de población, como sobre la estructura por edad del conjunto de la población afincada en Málaga. La información que hemos empleado proviene de los registros padronales del Ayuntamiento de Málaga correspondientes a 2003 -primer año para el que la información 
fue recabada al nivel de desagregación espacial que hemos empleado, el barrio- y 2010, última fecha disponible en el momento de escribir estas líneas, en los que quedan recogidos, entre otros datos, la nacionalidad de cada uno de los empadronados en el municipio a fecha de 1 de enero.

Como anteriormente indicamos, uno de los mayores desafíos que enfrenta cualquier estudio de diferenciación residencial de la población es la unidad espacial a la que quedará referida la información de la que se dispone. En el caso español, son las secciones censales las unidades más empleadas, desde el momento en que obtener series temporales de información relevante referida a ellas es relativamente sencillo al ser la unidad espacial utilizada por el INE. No obstante, hay otras unidades espaciales que también han sido usadas, como los barrios o agrupaciones de barrios "ad hoc" realizadas por diferentes organismos, por lo general de ámbito municipal; unidades espaciales alternativas de uso mucho más limitado no sólo por la dificultad de obtener información relevante referida a ellas -en el caso de que ésta exista-, sino por el hecho de que no todos los municipios cuentan con una delimitación diferente a la de distritos y secciones censales, lo que dificulta la realización de estudios comparados aún entre municipios vecinos.

De cualquier forma, si bien es cierto que cualquiera que sea la elección de la unidad espacial de referencia conlleva toda una serie de inconvenientes ${ }^{1}$, creemos que también lo es el que, al menos en nuestro caso, la elección del barrio trae consigo ventajas frente a la sección censal. Una de ellas es que, una vez establecidos, sus límites se mantienen estables, delimitándose la aparición de nuevos barrios habitados sobre porciones de diseminados o sobre áreas hasta entonces no habitadas del continuo construido. Por tanto, el empleo del barrio permite dar cuenta con bastante precisión del impacto sobre la población de procesos de cambios de uso del suelo, por ejemplo de industrial o equipamientos a residencial, que probablemente quedarían difuminados de emplear la sección censal. Además, este mantenimiento de los límites nos salvaguarda de los procesos análogos al surgimiento de nuevas secciones tanto por división de otras preexistentes -fenómeno común en las periferias de la mancha urbana cuando se alcanzan determinados umbrales de población-, como de la aparición de otras por la adición de otras preexistentes - proceso cada vez más frecuente en unas áreas centrales con cada vez menor número de habitantes en su interior-. Esta permanencia presenta además la ventaja de que pueden rastrearse procesos de renovación urbana -y sus consecuencias sobre la población- de áreas centrales o pericentrales, de importancia y que afectan a barrios tradicionales degradados que, una vez más, quedarían embutidos en la o las secciones censales correspondientes. Siendo todo ello así, las ganancias, pérdidas o cambios en la composición interna de la población de los barrios puede asegurarse que no están influenciadas por modificaciones en la unidad espacial (puesto que permanece inmutable), estando razonablemente seguros de que dichos cambios deben achacarse más a la evolución del individuo urbano que a los cambios experimentados en la división administrativa de su interior.

${ }^{1}$ Sobre las ventajas e inconvenientes del uso del barrio y la sección censal en los estudios de microanálisis social urbano puede consultarse a Ocaña (2005a). 
Para la delimitación efectiva de los barrios del municipio, el Centro Municipal de Informática (CEMI) del Ayuntamiento malagueño ha empleado diferentes criterios: delimitación contenida en los proyectos de urbanización, tipología de las viviendas, límites históricos ampliamente aceptados, usos del suelo -diferenciando usos industriales o grandes equipamientos de los usos residenciales, por ejemplo-, etc. En 2003 existía un total de 323 barrios habitados, que habían aumentado a 373 en 2010; unas cifras no demasiado diferentes de las correspondientes a las secciones censales, 420 en 2004 y 428 en 2009. Para nuestro estudio hemos considerado un total de 352 barrios, puesto que hemos suprimido los barrios correspondientes a polígonos industriales, zonas de equipamiento (universitario, comercial, recreativo, etc.), o grandes infraestructuras, que pese a su naturaleza, contaban con población empadronada (en todos los casos menos de 10 personas), pero que no pueden considerarse como residenciales ni siquiera de manera marginal.

\section{LA EVOLUCIÓN DEL VOLUMEN DE LA POBLACIÓN EXTRANJERA EN MÁLAGA Y SU DISTRIBUCIÓN ESPACIAL}

Antes de centrarnos en la influencia que la llegada de inmigrantes ha tenido sobre el volumen de población y la estructura por edad del municipio malagueño, es preciso dar un repaso, siquiera sea breve, a la evolución de sus cifras y a las características de su distribución espacial en el interior del entramado urbano malagueño.

Según indican las cifras oficiales del Padrón Municipal de Habitantes, la evolución de la población del municipio de Málaga desde 1998 ha sido ligeramente ascendente, con un repunte en el volumen de crecimiento a partir de 2003. Y, tal y como se aprecia en la tabla 1, es el contingente de extranjeros el que ha aportado la porción mayoritaria a este incremento de población; en la serie temporal que estamos considerando su evolución ha sido positiva, o muy positiva, con la única excepción de 2007; en contraste, la pauta de evolución de la población española ha sido mucho más errática, coexistiendo años de incremento con otros de descenso en sus contingentes. Como consecuencia de ello, si en estos 13 años la población extranjera empadronada en el municipio de Málaga se ha multiplicado por diez, hasta alcanzar los 47.769 empadronados, la española se ha incrementado únicamente en algo menos de 6.000 personas. Y debido a este aumento diferencial de población, la tasa de extranjería se ha elevado al $8,27 \%$, un valor relativamente escaso en comparación con otros municipios españoles ${ }^{2}$, pero que en tan sólo 7 años, los que van de 2003 a 2010, prácticamente se ha doblado (cfr. tabla 1). En consecuencia, puede afirmarse que el grueso del aumento de población que ha experimentado el municipio de Málaga se debe a los aportes de los empadronados extranjeros; de los 49.016 empadronados más que había en 2010 con respecto a 1998, nada menos que 43.101 se deben a nuevos empadronados

${ }^{2}$ En 2010, y según información del INE, 17,46\% en el municipio de Barcelona; $17,36 \%$ en el de Madrid, y $14,79 \%$ en el de Valencia. Sin embargo, este valor está al mismo nivel que el correspondiente al municipio de Bilbao (8,03\%) y muy por encima del de Sevilla (5,3\%), por citar tan sólo los municipios centrales de las seis metrópolis mayores de España, entre las que se encuentra Málaga. 
extranjeros, y tan sólo 5.915 se deben a aportes de españoles. Y desde 2003, año de comienzo de nuestro estudio, la práctica totalidad del aumento de población se debe a los extranjeros.

Tabla 1. Evolución de la población del municipio de Málaga, discriminada por origen $(1998 / 2010)$.

\begin{tabular}{|l|r|r|c|r|}
\hline Padrón & Extranjeros & Españoles & Total & \% extranjeros \\
\hline 1998 & 4.668 & 523.411 & 528.079 & 0,88 \\
\hline 1999 & 5.140 & 525.413 & 530.553 & 0,97 \\
\hline 2000 & 6.226 & 525.339 & 531.565 & 1,17 \\
\hline 2001 & 8.351 & 525.856 & 534.207 & 1,56 \\
\hline 2002 & 11.722 & 523.964 & 535.686 & 2,19 \\
\hline 2003 & 17.920 & 536.688 & 554.608 & 3,23 \\
\hline 2004 & 23.515 & 534.750 & 558.265 & 4,21 \\
\hline 2005 & 30.233 & 530.522 & 560.755 & 5,39 \\
\hline 2006 & 39.289 & 534.620 & 573.909 & 6,84 \\
\hline 2007 & 37.843 & 536.510 & 574.353 & 6,58 \\
\hline 2008 & 43.252 & 533.473 & 576.725 & 7,5 \\
\hline 2009 & 46.158 & 531.726 & 577.884 & 7,98 \\
\hline 2010 & 47.769 & 529.326 & 577.095 & 8,27 \\
\hline
\end{tabular}

Fuente: INE y Ayuntamiento de Málaga. Datos padronales a 1 de enero. Elaboración propia.

Este incremento del volumen de población extranjera en el municipio de Málaga debe enmarcarse en lo que se ha venido a denominar "proceso de centralización" de la población extranjera en el conjunto del área metropolitana malagueña (Fullauondo, 2007). Así, si bien serían sus municipios periféricos ${ }^{3}$ los que proporcionalmente contendrían un volumen de extranjeros mayor en relación con el municipio central, desde 2001 los mayores volúmenes de población no española se habrían dirigido hacia éste último, desembocando en un aumento del peso de la ciudad central en detrimento de la periferia. Esta situación de presencia de extranjeros -con motivaciones básicamen-

${ }^{3}$ La delimitación del área metropolitana malagueña que emplea el autor es la del Ministerio de la Vivienda, fechada en 2005, e incluye a Málaga, como municipio principal, más Torremolinos, Benalmádena, Fuengirola, Mijas, Rincón de la Victoria, Cártama y Alhaurín de la Torre. Los cuatro primeros municipios forman parte del núcleo de la Costa del Sol Occidental, y la presencia en ellos de población europea es de larga data. 
te residenciales- en los municipios aledaños a Málaga ya había sido puesto de manifiesto por Ocaña en los ochenta, indicando que tan sólo en Torremolinos (entonces todavía incluido en el municipio de Málaga) este segmento de población tenía alguna representación notable, mientras que al interior de Málaga capital tan sólo áreas muy concretas y escasas, como La Palmilla, Miraflores de los Ángeles o La Malagueta, contaban con algunos contingentes reseñables (Ocaña, 1988). Sin embargo, la nueva -e importante- corriente inmigratoria hacia España ha venido espoleada por una demanda de puestos de trabajo encuadrados en servicios personales, pero también a una demanda de mano de obra, sin demasiada cualificación, por parte de construcción y hostelería, lo que ha incrementado notablemente el flujo de inmigrantes a España (Leal, 2007) y, desde luego, al municipio de Málaga; y es en este contexto en el que debemos integrar la llegada de los contingentes de extranjeros al municipio de Málaga desde comienzos de este siglo, un proceso reciente y en el que los inmigrantes laborales son los grandes protagonistas de la corriente inmigratoria (Carvajal, 2005).

Volviendo a la localización de los extranjeros en el municipio capital, si bien es cierto que en la práctica totalidad de los barrios malagueños hay empadronado algún extranjero, también lo es el hecho de que su distribución espacial en el tejido urbano malagueño dista de ser uniforme, como tampoco es uniforme el peso que representan en el total de la población de los barrios de la capital. Muestra de ello es la información contenida en la figura 1, en la que representamos las tasas de extranjería correspondientes a 2010 .

Figura 1. Tasas de extranjería en los barrios del municipio de Málaga (2010).

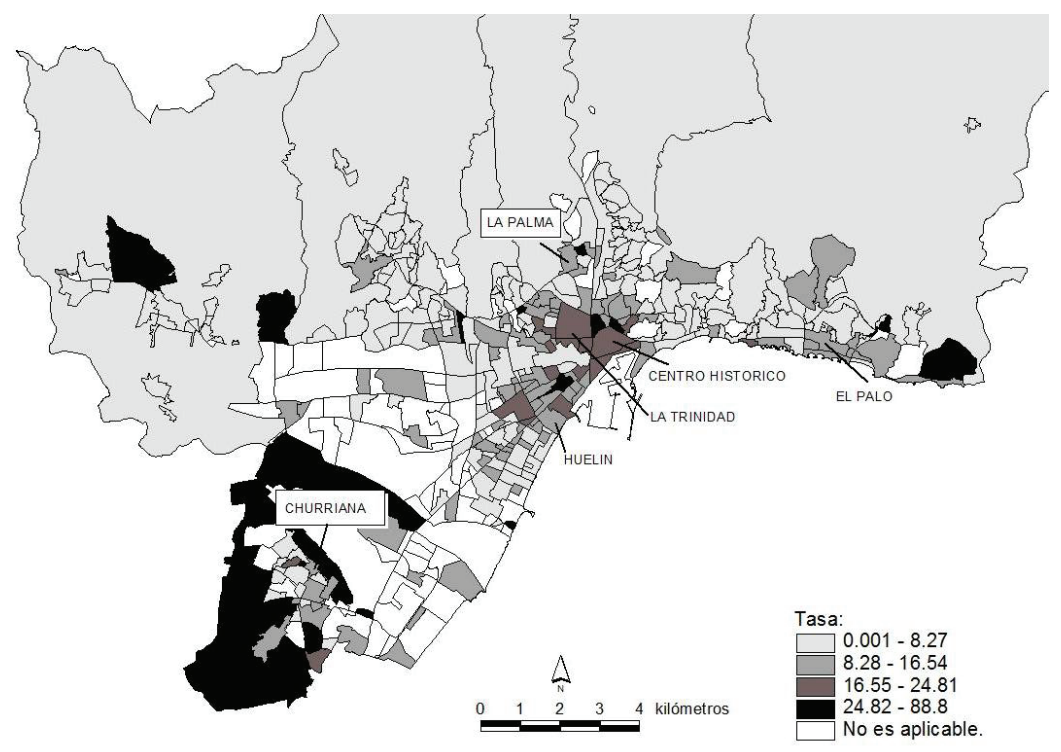

Fuente: Datos padronales a 1 de enero. Elaboración propia. 
En 2010 los barrios con una tasa de extranjería superior al 8,27\% (la tasa correspondiente al conjunto del municipio ese año) se extendían por una amplia zona que engloba el centro de la ciudad y los barrios situados inmediatamente al norte del mismo. Desde aquí, aparecen dos alineaciones de barrios con tasas de extranjería también superiores al conjunto municipal, una hacia el noroeste, que comprende los barrios de la expansión histórica del centro más allá del Guadalmedina (Trinidad, Perchel...), y otra hacia el sur oeste, en dirección también a expansiones obreras de la ciudad, pero surgidas con posterioridad a las anteriores (Huelin, Jardín de la Abadía...). Desconectados espacialmente de este gran conjunto, hay otros, como el localizado al norte del mismo, sobre barrios como La Palma o 26 de Febrero, piezas de una zona identificada como una de las más degradadas de la ciudad; el situado en el entorno de El Palo, sobre el litoral oriental, antiguo núcleo de población unido por coalescencia al principal; y, en el extremo oeste, la barriada de Churriana y su entorno -incluyendo su diseminado- presenta también tasas de extranjería superiores -muy superiores en algunos casos-a la del conjunto municipal.

Pareciera ser un hecho que la localización exacta de estas concentraciones responde en gran medida a la disponibilidad de vivienda asequible, $y$, en este sentido, tal y como indica Martínez (1999) una vez que se alcanza un "número crítico" de inmigrantes residiendo en un lugar de la ciudad, esto funciona como una señal para otros miembros del grupo de que ahí hay vivienda más o menos disponible; abundando en ello, es interesante indicar que en el caso de Sevilla si bien son tres las razones -los componentes- que subyacen en la localización espacial de los inmigrantes, el que mayor peso tiene es la existencia previa de familiares, amigos o conocidos en el barrio (Huete y Muñoz, 2010), lo que está en la base de los procesos de agrupamiento de los inmigrantes en el espacio urbano. En este sentido, en el caso concreto de Málaga se ha apuntado (Ocaña 2005b), que las concentraciones de empadronados extranjeros a las que acabamos de hacer referencia responden más a un proceso de acumulación relativa que a una situación de exclusión o aislamiento con respecto a la población local.

Una vez evidenciados la distribución e importancia de la población extranjera en los barrios malagueños, podemos comenzar a dar cuenta de los objetivos de la presente contribución, comenzando por la estimación que la llegada de la población extranjera ha tenido sobre la evolución de la población residente en los diferentes barrios de la capital malagueña.

\section{PRESENCIA DE EXTRANJEROS Y EVOLUCIÓN DEL CONJUNTO DE POBLACIÓN}

Como en los párrafos anteriores hemos indicado, el municipio de Málaga ha experimentado un aumento de su población entre 2003 y 2010, comportamiento alcista que, sin embargo, no es extrapolable a la totalidad de los barrios en los que se divide, antes al contrario. Así, y si bien es cierto que el grueso de los 352 barrios malagueños ha experimentado un aumento en su número de empadronados (196 
barrios, el 55,7\% del total), también lo es el que algo más de las dos quintas partes de estas unidades espaciales han sufrido un descenso de población $(154,43,8 \%)$; el resto ( 2 barrios) la han mantenido, aunque hemos de indicar que en ambos casos se trata de barrios con volúmenes muy exiguos de población. Por tanto, y como cabría esperar, el aumento global de la población empadronada en Málaga no se ha distribuido de manera homogénea en el entramado municipal, tal y como puede apreciarse con claridad en la figura 2 .

A partir de la información contenida en ella, podemos identificar varias agrupaciones de barrios que han experimentado un descenso de población entre 2003 y 2010. La más importante de ellas describe un gran arco que rodea, de forma relativamente fragmentaria, el centro de la ciudad y alguna de sus expansiones históricas; este arco se extiende desde la porción del litoral oriental más cercana al centro, que incluye alguno de los barrios considerados como de mejor calidad residencial en el imaginario urbano (El Limonar, la Malagueta, sobre la playa del mismo nombre), continua hacia el norte del continuo construido a través de Ciudad Jardín y su entorno (incluyendo su diseminado), y se extiende hacia el oeste a través de un conjunto de barrios de diferente origen, articulados por las Avenidas de Andalucía (Polígono Alameda, Carranque) y de la Aurora, para cerrarse en las barriadas localizadas inmediatamente a espaldas del litoral occidental, barriadas tanto de orígenes autárquicos (Girón) como posteriores, pero teniendo todas en común su pertenencia a la expansión "obrera" de la ciudad hacia el oeste. La continuidad espacial de este arco es, a nuestro entender, bastante notable, especialmente en su porción sudoccidental, quedando rota de manera más marcada en la porción occidental por un conjunto de barrios situados al oeste de la Trinidad, y articulados por la calle Mármoles y el Camino de Antequera, vías naturales de comunicación del continuo construido hasta los noventa con las nuevas -e importantes- expansiones residenciales, en el en entorno del Campus Universitario de Teatinos.

Las restantes agrupaciones de barrios con pérdidas absolutas se corresponden con los localizados en el entorno de núcleos tradiciones de población del municipio, unidos por coalescencia al principal, como El Palo (en el litoral oriental), y, de norte a sur en el extremo occidental, el Puerto de la Torre, Campanillas y Churriana (estos dos últimos incluyendo sus diseminados). Con la única excepción de Churriana, el proceso de pérdida neta de población no afecta al núcleo originario, tan sólo a los barrios surgidos en su entorno con posterioridad, de manera que el área de vivienda más antigua ha experimentado un proceso opuesto al de las expansiones posteriores.

Por su parte, los barrios localizados en el resto del municipio han experimentado una dinámica de población positiva, y de entre todos ellos debe destacarse el caso del centro y sus expansiones históricas hacia el norte, este y oeste, que dibujan un área de crecimiento poblacional positivo - en algunos casos, muy positivo-, en pleno centro de la ciudad y en sus áreas aledañas. 
Figura 2. Dinámicas de la evolución de la población total de los barrios malagueños (2003/2010).

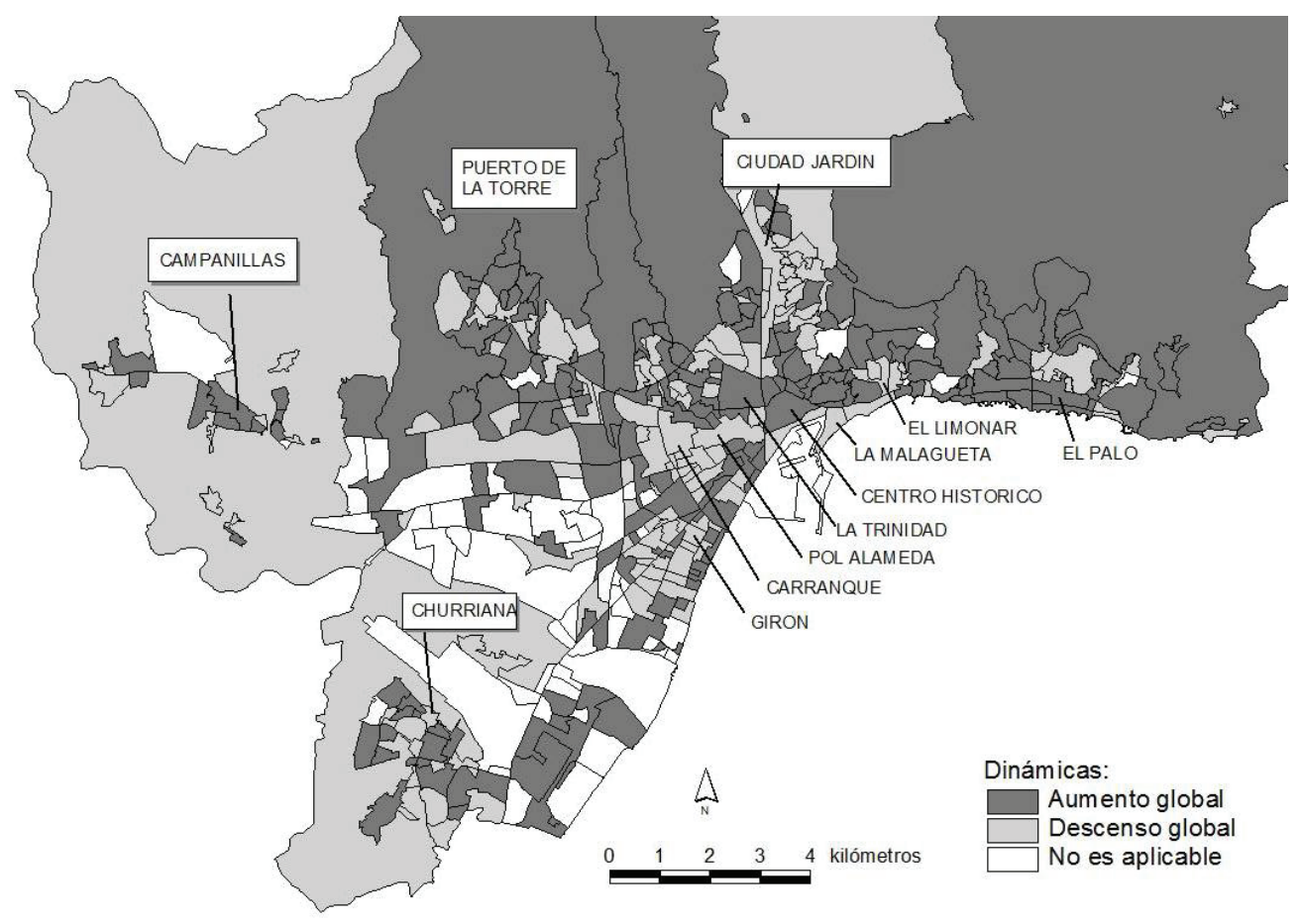

Fuente: Registros padronales a 1 de enero. Elaboración propia.

Dibujada a grandes rasgos la situación general, cabe plantearse cuál ha sido la influencia de los aportes de los empadronados extranjeros en ella, unos aportes extranjeros sin los que, recordemos, el volumen de la población empadronada en el municipio habría descendido en nuestro periodo de estudio. Para tratar de dar respuesta a esta cuestión hemos tabulado las dinámicas que podrían identificarse en los distintos barrios de la ciudad; estas dinámicas surgen de la combinación del comportamiento de los volúmenes de la población total, de la española y de la extranjera, comportamientos que pueden ser de crecimiento, descenso o mantenimiento. Las 13 combinaciones que están presentes en los 352 barrios malagueños han sido resumidas en siete grupos, cuya presencia en los barrios detallamos en la tabla 2. 
Tabla 2. Dinámicas de evolución de la población de los barrios malagueños.

\begin{tabular}{|l|l|r|}
\hline Dinámica & Descripción & N. Barrios \\
\hline Aumento absoluto & $\begin{array}{l}\text { Aumento de la población española y de la } \\
\text { extranjera }\end{array}$ & $\begin{array}{r}133 \\
(37,8 \%)\end{array}$ \\
\hline $\begin{array}{l}\text { Aumento con } \\
\text { extranjerización }\end{array}$ & $\begin{array}{l}\text { Aumento de la población total y de la } \\
\text { extranjera, con descenso de la española }\end{array}$ & $\begin{array}{r}49 \\
(13,9 \%)\end{array}$ \\
\hline $\begin{array}{l}\text { Aumento sin } \\
\text { extranjeros }\end{array}$ & $\begin{array}{l}\text { Aumento de la población total y de la española, } \\
\text { sin presencia de extranjeros }\end{array}$ & $7(1,9 \%)$ \\
\hline Descenso absoluto & $\begin{array}{l}\text { Descenso de la población española y de la } \\
\text { extranjera }\end{array}$ & $10(2,8 \%)$ \\
\hline $\begin{array}{l}\text { Descenso con } \\
\text { extranjerización }\end{array}$ & $\begin{array}{l}\text { Descenso de la población total y de la española, } \\
\text { con aumento de la población extranjera }\end{array}$ & $\begin{array}{r}130 \\
(36,9 \%)\end{array}$ \\
\hline $\begin{array}{l}\text { Descenso sin } \\
\text { extranjeros }\end{array}$ & $\begin{array}{l}\text { Descenso de la población total y de la española, } \\
\text { sin presencia de extranjeros }\end{array}$ & $10(2,9 \%)$ \\
\hline Otras dinámicas & Resto de combinaciones posibles (7) & $13(3,8 \%)$ \\
\hline
\end{tabular}

Fuente: Elaboración propia.

En dicha tabla se observa cómo algo más de un tercio de los barrios malagueños ha experimentado un aumento de población desde 2003 (dinámica de aumento absoluto), al que han contribuido tanto españoles como extranjeros; al tiempo que en otros 7 (dinámica de aumento sin extranjeros) el aumento se ha debido exclusivamente de la llegada de empadronados españoles, al no existir población foránea empadronada en ellos. En relación con ello, es necesario indicar que la totalidad de estos últimos 7 barrios agrupan volúmenes de población muy exiguos -incluso cuatro de ellos no contaban con población en 2003-, pudiéndose calificar tan sólo de forma residual como residenciales. De cualquier forma, el hecho es que estas dos dinámicas son las únicas presentes en el municipio que implican aumentos en todos los grupos de población involucrados, aunque en la segunda de ellas tan sólo haya empadronados españoles; el resto, traen aparejada la pérdida de población por parte de al menos uno de los dos contingentes, aunque esto no necesariamente implica pérdidas absolutas de población. Es así que la dinámica que hemos denominado "Aumento con extranjerización" es indicativa de un aumento de los extranjeros de tal magnitud que no sólo ha sido suficiente como para enjugar las pérdidas registradas de población nacional, sino que ha derivado en un saldo final positivo; una dinámica que etiqueta a un total de 49 barrios de la capital, resolviéndose como la cuarta en importancia (cfr. tabla 2).

Cuando la llegada de extranjeros a un barrio no es suficiente como para enjugar las pérdidas de españoles -como ocurría en la dinámica anterior-, entonces la dinámica 
poblacional pasa a ser de "Descenso con extranjerización"; esta dinámica afecta a más de un tercio de los barrios malagueños (cfr. tabla 2), y uniéndola a la correspondiente al "aumento con extranjerización", implica que en más de la mitad de los barrios de nuestro municipio se ha registrado un proceso de sustitución de población española por foránea.

Figura 3. Dinámicas de la evolución de la población total de los barrios malagueños según el origen de la población $(2003 / 2010)$.

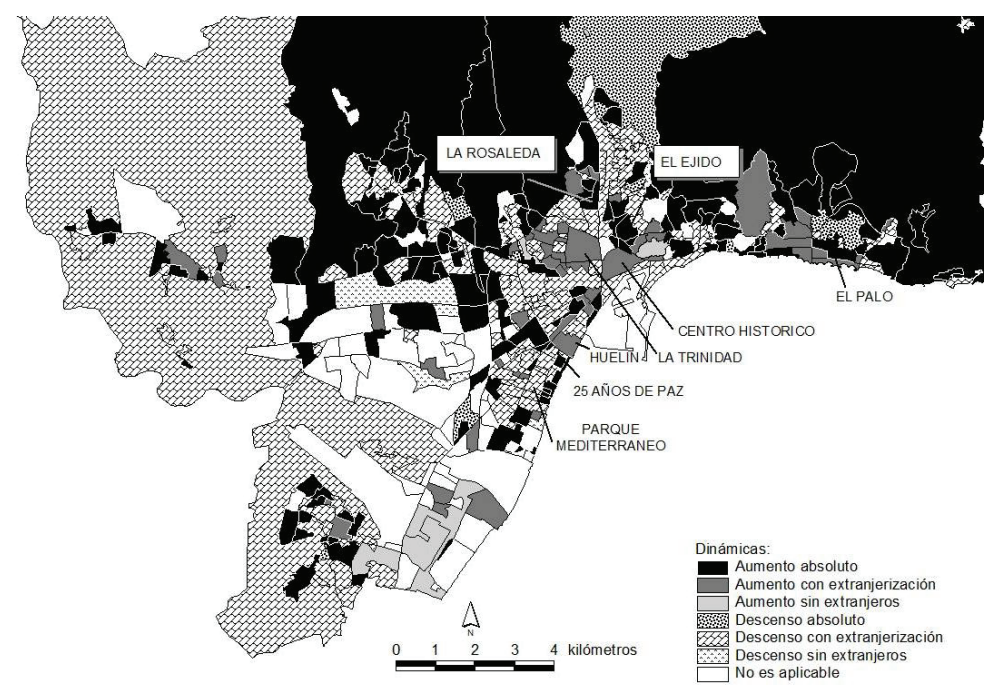

Fuente: Registros padronales a 1 de enero. Elaboración propia.

Podemos cartografiar estas dinámicas, y el resultado se muestra en la figura 3. Tal vez lo que pueda llamar la atención de manera más clara sea la extensión y el grado de contigüidad espacial de los barrios en los que se ha registrado el mencionado proceso de sustitución de población: éste no se circunscribe únicamente al centro de Málaga, como en principio podría esperarse, sino que se extiende prácticamente sin solución de continuidad hacia el norte, en el entorno de Ciudad Jardín, y hacia el oeste, no sólo a través de las expansiones históricas del Centro en esta dirección -Trinidad, Perchel, Huelin-, sino también por gran parte del tejido construido articulado tanto por el Camino de Antequera, la Avenida de Andalucía y la antigua Carretera de Cádiz, tanto sobre barriadas autárquicas -Carranque, 25 Años de Paz, Girón-, como sobre otras más recientes, y heterogéneas en su origen -Polígono Alameda, Mainake o Parque Mediterráneo, por citar sólo tres ejemplos-. Todos estos barrios conforman un área, notable por su extensión y compacidad, de mayor desarrollo hacia las antiguas periferias obreras de la ciudad, y que indudablemente se resuelve como una de las cristalizaciones espaciales más relevantes de la evolución reciente de la población malagueña. 
Este proceso de sustitución también está presente en el litoral oriental, tradicionalmente una de las zonas residenciales más valoradas de la capital, pero su cristalización espacial no es ni tan amplia ni tan continua como las anteriores, orbitando alrededor del núcleo tradicional de población de esta zona, El Palo. Por su parte, también son los núcleos de población tradicionales del extremo occidental del municipio los que articulan grupos de barrios que están experimentando este proceso de sustitución, y a los que anteriormente ya hicimos referencia: Churriana, Campanillas y el Puerto de la Torre; éste último es el menos llamativo visualmente de los tres casos al no al no estar afectado su diseminado (afectado por una dinámica de aumento absoluto).

Vistas así las cosas, los barrios etiquetados con dinámica de crecimiento absoluto se localizan en la periferia occidental del continuo construido (sobre las grandes ampliaciones del entorno del Campus Universitario de Teatinos), en el tejido urbano recientemente renovado del litoral occidental, en la porción oriental del municipio, y en áreas muy concretas del pericentro malagueño, destacando las correspondientes al entorno de El Ejido y La Rosaleda, que rompen la continuidad espacial de los barrios afectados por el proceso de sustitución de población española por extranjera.

Como en párrafos anteriores indicamos, no cabe duda de que en esta distribución espacial de las dinámicas de evolución de la población, las características de las viviendas, $\mathrm{y}$ las diferentes posibilidades de acceso a la misma, juegan un papel fundamental. En este sentido, debemos recordar el hecho de que el nivel de recursos del individuo -o del hogar en el que se inserta- guarda una íntima relación con las características de la vivienda a la que puede optar, por lo que las personas con los ingresos más bajos estarían residiendo en las viviendas de peores características, ya sean características objetivas propias de la vivienda, o relacionadas con las características que tiene en el imaginario social el barrio en el que localiza; una relación que, si bien podría esperarse que cambiase en determinados estados del bienestar europeos -debido a la presencia de programas sociales de control de alquileres, subsidios, e incluso a la presencia de un sector público de alquiler- (Kempen y Özüekren, 1998), no parece corresponderse con el caso de España en su conjunto (Arbaci, 2007) ni de Málaga en particular: por tanto, la relación nivel de renta características -y localización- de la vivienda, debiera ser fuerte en nuestro municipio.

Así se desprende del hecho de que los barrios donde los inmigrantes están sobre representados -que coinciden en gran medida con los barrios afectados por el proceso de sustitución de población antes aludido-, están localizados en las áreas donde el peso de la vivienda de baja calidad es mayor: centro (con un 20,8\%), litoral oeste $(21,4 \%)$, prolongación de la Alameda (20\%) y Rosaleda (20,5\%) -cfr. Ocaña, 2005: 127-129-. Por otro lado, la forma de acceso a la vivienda por parte de una porción significativa de este conjunto de población es el alquiler, dado su desfavorable posición en relación con el mercado de la vivienda derivada de su carencia de patrimonio previo y los recursos limitados con los que cuentan. Así, se ha indicado que el acceso a la propiedad de la vivienda por parte de los extranjeros en el municipio de Málaga suele suceder tras un periodo de residencia no menor de 6 años (Ocaña, 2008), por lo 
que podemos suponer que una porción muy significativa de los nuevos inmigrantes empadronados en Málaga en 2010 residían en alquiler.

Esta relación entre existencia de viviendas de baja calidad -con una proporción significativa del alquiler o de la no ocupación- y presencia de inmigrantes económicos también ha sido puesta de manifiesto en otros municipios españoles, como es el caso de Madrid. Es así que en este municipio durante los noventa se registró un cambio en los procesos segregativos de la población, debido tanto a la concentración en determinadas áreas de la ciudad de los grupos de población de mayores ingresos, como a la concentración de los trabajadores extranjeros en ciertas zonas caracterizadas por la abundancia de vivienda en alquiler a precios medios y bajos (Leal, 2007). También en Bilbao el grueso de los inmigrantes se localiza en barrios con viviendas degradadas, como San Francisco y Bilbao la Vieja, las zonas más degradadas del centro bilbaino (Lavía, 2008).

Volviendo a Málaga, y centrándonos en el otro extremo de la escala, el grueso de la vivienda nueva se ha levantado en las áreas periféricas, básicamente en el sector occidental del municipio (entorno de Teatinos, Litoral Oeste), en su mayor parte vivienda libre de elevados precios y es en ellas donde, como hemos indicado, se registra el grueso de las situaciones de aumento de la población sin presencia de extranjeros (cfr. Figura 2). Por su parte, la escasa presencia del proceso de sustitución de población observada en el litoral oriental viene dada, entre otras razones, por los comparativos elevados precios de la vivienda en esta zona y sus, en general buenas calidades; en este sentido, es importante señalar que los barrios clasificados con la tendencia de "Aumento con extranjerización" se localizan en el entorno de El Palo, precisamente un área en la que las condiciones medias de las viviendas son considerablemente más bajas que en el resto de los barrios encuadrados en esta zona.

\section{LA INFLUENCIA SOBRE LA ESTRUCTURA POR EDAD}

La evolución de la estructura por edad de la población empadronada en Málaga desde 2003 ha venido caracterizada por un ligero aumento del porcentaje tanto de niños como de ancianos, a expensas del peso correspondiente al grupo de los adultos (cfr. tabla 3). Discriminando a la población por origen, la española ha experimentado este mismo comportamiento ${ }^{4}$, al tiempo que el contingente extranjero se ha visto afectado por un proceso de rejuvenecimiento tanto por la base como por la cúspide; y aunque ciertamente el peso de los adultos extranjeros ha disminuido ligeramente en nuestro periodo de estudio, el hecho de que más de las cuatro quintas partes de los empadronados estén encuadrados en él es consistente con las motivaciones inmigratorias netamente laborales a las que en los párrafos anteriores hicimos referencia.

${ }^{4}$ Vista la comparativamente reducida proporción de extranjeros existente en nuestro municipio, no debe extrañar el hecho de que tanto la estructura por edad del conjunto de la población afincada en él, como su evolución reciente, estén básicamente influidas por el comportamiento del contingente nacional 
Tabla 3. Distribución en grandes grupos de edad de la población total, española y extranjera empadronada en el municipio de Málaga (2003/2010).

\begin{tabular}{|l|r|r|r|r|r|r|}
\hline \multirow{2}{*}{$\begin{array}{l}\text { Grupo } \\
\text { de edad }\end{array}$} & \multicolumn{2}{|c|}{ Españoles } & \multicolumn{2}{c|}{ Extranjeros } & \multicolumn{2}{c|}{ Total población } \\
\cline { 2 - 7 } & \multicolumn{1}{|c|}{2003} & 2010 & 2003 & 2010 & \multicolumn{1}{c|}{2003} & \multicolumn{1}{c|}{2010} \\
\hline $0-14$ & $\begin{array}{r}79.581 \\
(14,83 \%)\end{array}$ & $\begin{array}{r}80.338 \\
(15,18 \%)\end{array}$ & $\begin{array}{r}2.199 \\
(12,27 \%)\end{array}$ & $\begin{array}{r}7.286 \\
(15,25 \%)\end{array}$ & $\begin{array}{r}81.780 \\
(14,75 \%)\end{array}$ & $\begin{array}{r}87.624 \\
(15,18 \%)\end{array}$ \\
\hline \multirow{2}{*}{$15-64$} & $\begin{array}{r}375.446 \\
(69,95 \%)\end{array}$ & $\begin{array}{r}359.866 \\
(67,98 \%)\end{array}$ & $\begin{array}{r}14.828 \\
(82,76 \%)\end{array}$ & $\begin{array}{r}38.978 \\
(81,6 \%)\end{array}$ & $\begin{array}{r}390.274 \\
(70,37 \%)\end{array}$ & $\begin{array}{r}398.844 \\
(69,12 \%)\end{array}$ \\
\hline \multirow{2}{*}{$65 \mathrm{y}+$} & $\begin{array}{r}81.661 \\
(15,22 \%)\end{array}$ & $\begin{array}{r}89.122 \\
(16,84 \%)\end{array}$ & $\begin{array}{r}891 \\
(4,97 \%)\end{array}$ & $\begin{array}{r}1.505 \\
(3,15 \%)\end{array}$ & $\begin{array}{r}82.552 \\
(14,88 \%)\end{array}$ & $\begin{array}{r}90.627 \\
(15,7 \%)\end{array}$ \\
\hline
\end{tabular}

Fuente. Datos padronales a 1 de enero. Elaboración propia.

La proporción que los extranjeros significan sobre el total de la población malagueña, y sobre los tres grandes grupos de edad en los que la hemos dividido, también ha experimentado ligeras variaciones desde 2003; así, si en ese año los extranjeros eran el 3,23\% del total de empadronados, los niños de este origen suponían el 2,68\%, los adultos el 3,79\% y los ancianos un exiguo $1,07 \%$, en 2010 esas proporciones eran del $8,31 \%, 9,77 \%$ y $1,66 \%$, respectivamente, siendo la tasa de extranjería de ese año el 8,27\%. Por tanto, el rejuvenecimiento de la población extranjera al que acabamos de hacer referencia ha implicado una sobrerrepresentación de los niños y los adultos -muy importante en el caso de estos últimos--, y una profundización de la condición residual de la proporción de ancianos.

De cualquier manera, y pese a estos hechos, resulta patente que la influencia que el contingente de extranjeros ha tenido sobre la evolución reciente de la estructura por edad de la población malagueña cuando se toma al municipio como un todo ha sido muy pequeña, debido al reducido porcentaje que suponen sobre la población total, recordemos, el 8,27\% en 2010. No obstante, y vista la desigual distribución en el espacio de este grupo de población, y el proceso de sustitución de españoles por extranjeros existente en un buen número de barrios de la capital, cabe preguntarse si, al descender al nivel del barrio, su influencia es palpable o no.

Para tratar de responder a esta pregunta, en primer lugar atenderemos a la evolución de la estructura por edad de la población total empadronada en los diferentes barrios malagueños, tomando en consideración únicamente la evolución (entendida como ascenso o descenso) del porcentaje de niños y ancianos, dejando a los adultos al margen. Partiendo de esta base, hemos identificado un conjunto de dinámicas, 
ofreciendo en la tabla 4 el significado de las cuatro con más presencia en los barrios malagueños, y el número de barrios en los que están presentes ${ }^{5}$.

Tabla 4. Número de barrios según la dinámica de evolución de la estructura por edad a la que pertenecen.

\begin{tabular}{|l|l|c|}
\hline Dinámica & Descripción & $\mathrm{N}^{\circ}$ de barrios \\
\hline $\begin{array}{l}\text { Rejuvenecimiento } \\
\text { absoluto }\end{array}$ & $\begin{array}{l}\text { Aumento del porcentaje de niños y } \\
\text { disminución del porcentaje de ancianos. }\end{array}$ & $61(19 \%)$ \\
\hline $\begin{array}{l}\text { Rejuvenecimiento } \\
\text { relativo }\end{array}$ & $\begin{array}{l}\text { Aumento de ambos porcentajes, quedando } \\
\text { en } 2010 \text { el porcentaje de niños por encima } \\
\text { del correspondiente al total de la ciudad } \\
(15,18 \%) \text { y el de ancianos por debajo } \\
(15,7 \%)\end{array}$ & $50(15,58 \%)$ \\
\hline $\begin{array}{l}\text { Envejecimiento } \\
\text { absoluto }\end{array}$ & $\begin{array}{l}\text { Disminución del porcentaje de niños y } \\
\text { aumento del porcentaje de ancianos }\end{array}$ & $138(42,99 \%)$ \\
\hline $\begin{array}{l}\text { Envejecimiento } \\
\text { relativo }\end{array}$ & $\begin{array}{l}\text { Aumento de ambos porcentajes, quedando } \\
\text { en 2010 el porcentaje de niños por debajo } \\
\text { del correspondiente al total de la ciudad } \\
(15,18 \%) \text { y el de ancianos por encima } \\
(15,7 \%)\end{array}$ & $46(14,33 \%)$ \\
\hline Resto & Resto de combinaciones posibles. & $26(8,1 \%)$ \\
\hline
\end{tabular}

Fuente: Elaboración propia.

En ella queda claramente marcado el hecho de que el grueso de los barrios malagueños ha experimentado un proceso de envejecimiento, ya sea absoluto o relativo; en contraste, tan sólo el 19\% ha experimentado un rejuvenecimiento tanto por la base como por la cúspide (rejuvenecimiento absoluto), mientras que el número de barrios en los que al menos se ha experimentado un rejuvenecimiento relativo es aún menor, tan sólo 50.

$\mathrm{Y}$, como en los casos anteriores, esta información puede cartografiarse, mostrando los resultados en la figura 4. En ella, y partiendo del centro de la ciudad, en dirección occidental, pueden identificarse tres orlas, correspondientes a barrios con dinámicas de rejuvenecimiento absoluto, de envejecimiento absoluto, y de rejuvenecimiento relativo, en ese orden. La primera de ellas se extiende a través del centro y sus expansiones históricas hacia el norte y oeste, conformando un bloque de notable continuidad espacial; la segunda es colindante con la anterior, y se extiende por lo que hasta hace pocos años ha

${ }^{5}$ El número de barrios considerados es de 321, un número menor que el correspondiente al epígrafe anterior (352); la razón para esta diferencia es que hay un total de 31 barrios que no contaban con empadronados en 2010 o en 2003. Sobre ellos es posible calcular la dinámica de evolución de los volúmenes de población, como así se ha hecho, pero entendemos que no tiene mucho sentido calcular la correspondiente a la estructura por edad. 
sido la periferia del continuo construido hacia el norte y el oeste; la continuidad espacial de estos barrios está rota por otros cuya población se ha rejuvenecido -en la mayor parte de los casos de manera absoluta- durante nuestro periodo de estudio, y vienen a corresponder a unidades espaciales encuadrables en el urbanismo autárquico ( 25 años de Paz, Carranque, Girón, etc.), piezas de comparativamente escasa calidad constructiva y faltas de equipamiento. Por último, es posible identificar una tercera orla, considerablemente más fragmentada que las dos anteriores, conformada por barrios con dinámica de rejuvenecimiento relativo, y que se corresponde básicamente con barrios de nueva planta reciente o muy recientemente construidos (Torre Atalaya, El Cónsul II...). Más allá de esta tercera orla, y siempre en dirección occidental, se localizan los núcleos periféricos (Puerto de la Torre, Campanillas y Churriana), afectados por una dinámica de envejecimiento absoluto en la mayor parte de los barrios en los que se dividen, con la única excepción de los que rodean al núcleo de Churriana, rejuvenecidos en diferentes proporciones en nuestro periodo de estudio.

Figura 4. Dinámicas de la evolución de la estructura por edad de la población de los barrios malagueños (2003/2010).

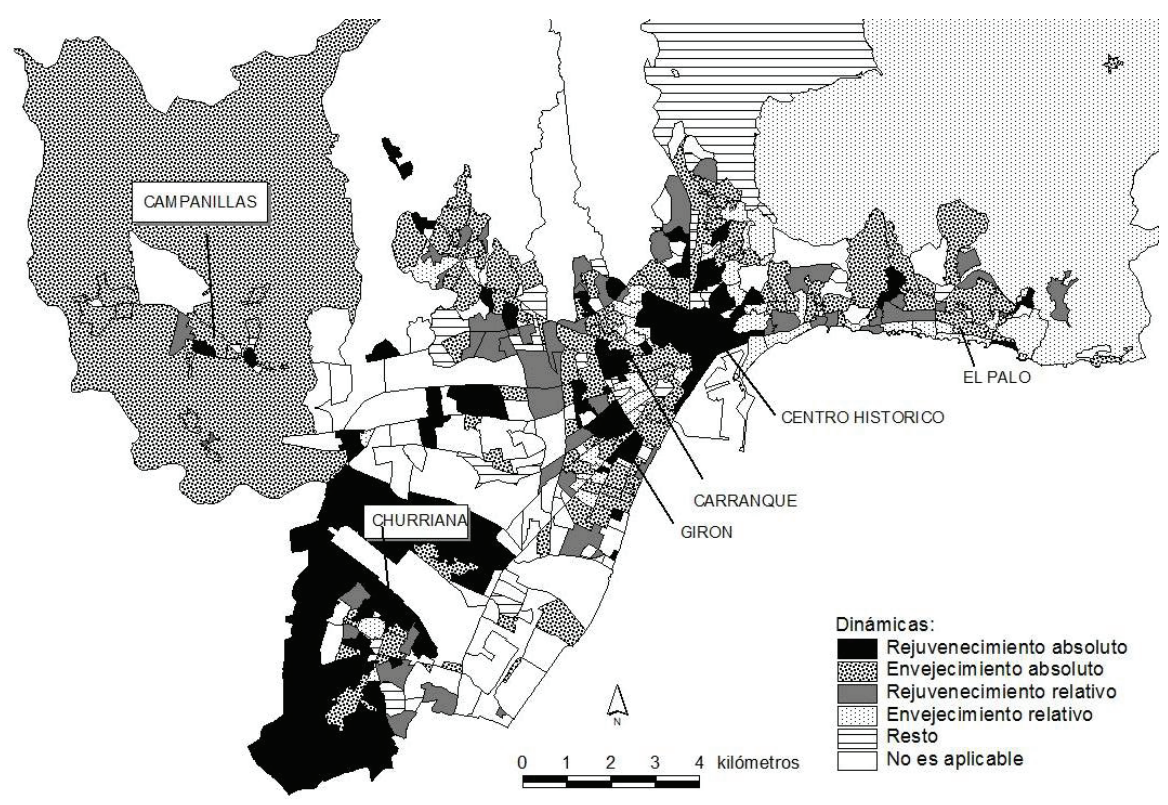

Fuente: Datos padronales a 1 de enero. Elaboración propia.

Así las cosas, esta distribución espacial es la que cabría esperar de la evolución de la población de cualquier asentamiento de cierto porte en el que sus áreas centrales se han visto sometidas a procesos de renovación de sus contingentes poblacionales. 
Por su parte, la situación correspondiente a los barrios localizados al este del centro es bastante más homogénea, el grueso de los mismos está afectado por una dinámica de envejecimiento, relativo en los litorales, básicamente absoluto en los interiores, incluyendo en esta dinámica de envejecimiento absoluto a los barrios delimitados sobre el antiguo núcleo de El Palo y su entorno inmediato. De este proceso de envejecimiento tan sólo escapa un grupo de barrios en el entorno de Pedregalejo, y algunos otros, ya aislados, asiento de actuaciones inmobiliarias relativamente recientes, dirigidas mayoritariamente a población de altos recursos -Lomas de San Antón, Jarazmín, etc.-

Siendo esta la situación general, interesa conocer cuál ha sido el impacto de la llegada de contingentes foráneos durante el periodo 2003/2010 sobre la estructura por edad de la población preexistente. Para cumplir con este objetivo hemos agrupado a los barrios en las mismas dinámicas anteriores, pero en este caso eliminando del cómputo a los extranjeros llegados en nuestro periodo de estudio ${ }^{6}$. De esta operación resulta el hecho de que son nada menos que 72 los barrios sobre los que la llegada de foráneos ha tenido alguna influencia sobre la estructura por edad, un número elevado (el 22,22\%) teniendo en cuenta el reducido porcentaje que este grupo supone sobre el total de la población malagueña; además, es importante señalar que la llegada de foráneos ha supuesto un proceso de rejuvenecimiento en 57 barrios, y de envejecimiento en los 15 restantes. Una panorámica más detallada de esta influencia la ofrecemos en la tabla 5, en la que, como puede observarse, eliminando los extranjeros del cómputo surgen dos nuevas dinámicas, que hemos denominado "Ligero envejecimiento" y "Ligero rejuvenecimiento".

Tabla 5. Número de barrios según la dinámica de evolución de la estructura por edad a la que pertenecen, excluyendo a los foráneos llegados entre 2003 y 2010.

\begin{tabular}{|l|c|c|c|c|c|c|c|}
\hline Dinámica & $\begin{array}{c}\text { Rejuvenec. } \\
\text { absoluto }\end{array}$ & $\begin{array}{c}\text { Envejec. } \\
\text { absoluto }\end{array}$ & $\begin{array}{c}\text { Rejuvenec. } \\
\text { relativo }\end{array}$ & $\begin{array}{c}\text { Envejec. } \\
\text { relativo }\end{array}$ & Resto & $\begin{array}{c}\text { Ligero } \\
\text { envejec. }\end{array}$ & $\begin{array}{l}\text { Ligero } \\
\text { rejuvenec. }\end{array}$ \\
\hline $\begin{array}{l}\text { Número } \\
\text { de barrios }\end{array}$ & 41 & 149 & 42 & 44 & 27 & 12 & 6 \\
\hline Diferencia & -20 & +11 & -8 & -2 & +1 & +12 & +6 \\
\hline
\end{tabular}

Fuente: Elaboración propia.

\footnotetext{
${ }^{6}$ El cálculo ha sido realizado de la siguiente manera: en primer lugar hemos sustraído a la población extranjera residente en 2010 en cada uno de los barrios aquella que fue empadronada en 2003, con lo que hemos obtenido el saldo neto de extranjeros para el periodo. Y es este saldo neto el que hemos restado de la población total empadronada en 2010 en cada uno de los barrios.

${ }^{7}$ La primera de ellas implica que el porcentaje de ancianos se incrementa más que el de los jóvenes, pero sin que la población del barrio alcance el porcentaje de ancianos del conjunto de la ciudad; la segunda, ligero rejuvenecimiento, aparece cuando el porcentaje de niños se incrementa más que el de ancianos, pero sin alcanzar finalmente el porcentaje de niños del conjunto de la ciudad.
} 
De la información contenida en ella debe destacarse el hecho de que numéricamente la influencia de los foráneos en nuestro periodo de estudio ha afectado principalmente a los barrios que experimentaron un proceso de rejuvenecimiento tanto por la base como por la cúspide (rejuvenecimiento absoluto); sin los aportes de extranjeros, su número se habría reducido en 20, y en 8 los barrios catalogados como con un proceso de rejuvenecimiento relativo. En contraste, los barrios afectados por un proceso de envejecimiento tanto por la base como por la cúspide (envejecimiento absoluto) se habrían incrementado en 11, pasando 12 más a sufrir un proceso de ligero envejecimiento.

Una vez más, hemos llevado a un mapa la distribución espacial de los procesos de rejuvenecimiento o envejecimiento anteriores, que mostramos en la figura 5. En ella puede observarse cómo el grueso de los barrios que han experimentado el primero de los procesos viene a conformar una orla, con bastante contigüidad espacial, y que agrupa a 23 de los 57 barrios rejuvenecidos por la presencia foránea. Esta orla rodea al centro de la ciudad por el norte (entornos de El Ejido y Ciudad Jardín) y por el oeste (Trinidad, Mármoles, Cruz de Humilladero), donde es rota tan sólo por el Polígono Alameda. En la mayor parte de los casos, las tasas de extranjerías correspondientes a estos barrios son bastante elevadas, por encima del $16 \%$ (cfr. figura 1), y, además, la mayor parte de estos barrios ha experimentado un proceso de evolución de sus contingentes de población caracterizado por el proceso de sustitución de población, ya sea con ganancias absolutas (dinámica de aumento con extranjerización en el entorno de La Trinidad) o con pérdidas absolutas (dinámica de descenso con extranjerización en el entorno de Ciudad Jardín y Cruz de Humilladero) -cfr. figura 3-. El resto de barrios rejuvenecidos se concentran, ya de manera mucho más dispersa, en el entorno de los núcleos del Puerto de la Torre, El Palo y Churriana, coincidiendo una vez más en la mayor parte de los casos rejuvenecimiento con proceso de sustitución de población española por extranjera.

Siendo así las cosas, la explicación del notable impacto que ha tenido la comparativamente reducida población extranjera sobre la estructura por edad de la población residente en un elevado número de barrios malagueños (recordemos, 72 sobre un total de 323 ), reside en gran medida en el proceso de sustitución de población al que en párrafos anteriores hicimos referencia. Este proceso ha magnificado el impacto local -a nivel de barrio- que ha tenido la llegada de extranjeros en estos últimos años, extranjeros que, por el contrario, no han sido capaces de influir de manera perceptible sobre la estructura por edad del conjunto de la población municipal, dada la desproporción existente entre nacionales y foráneos. 
Figura 5. Influencia de los extranjeros en las estructuras por edad de los barrios malagueños $(2003 / 2010)$.

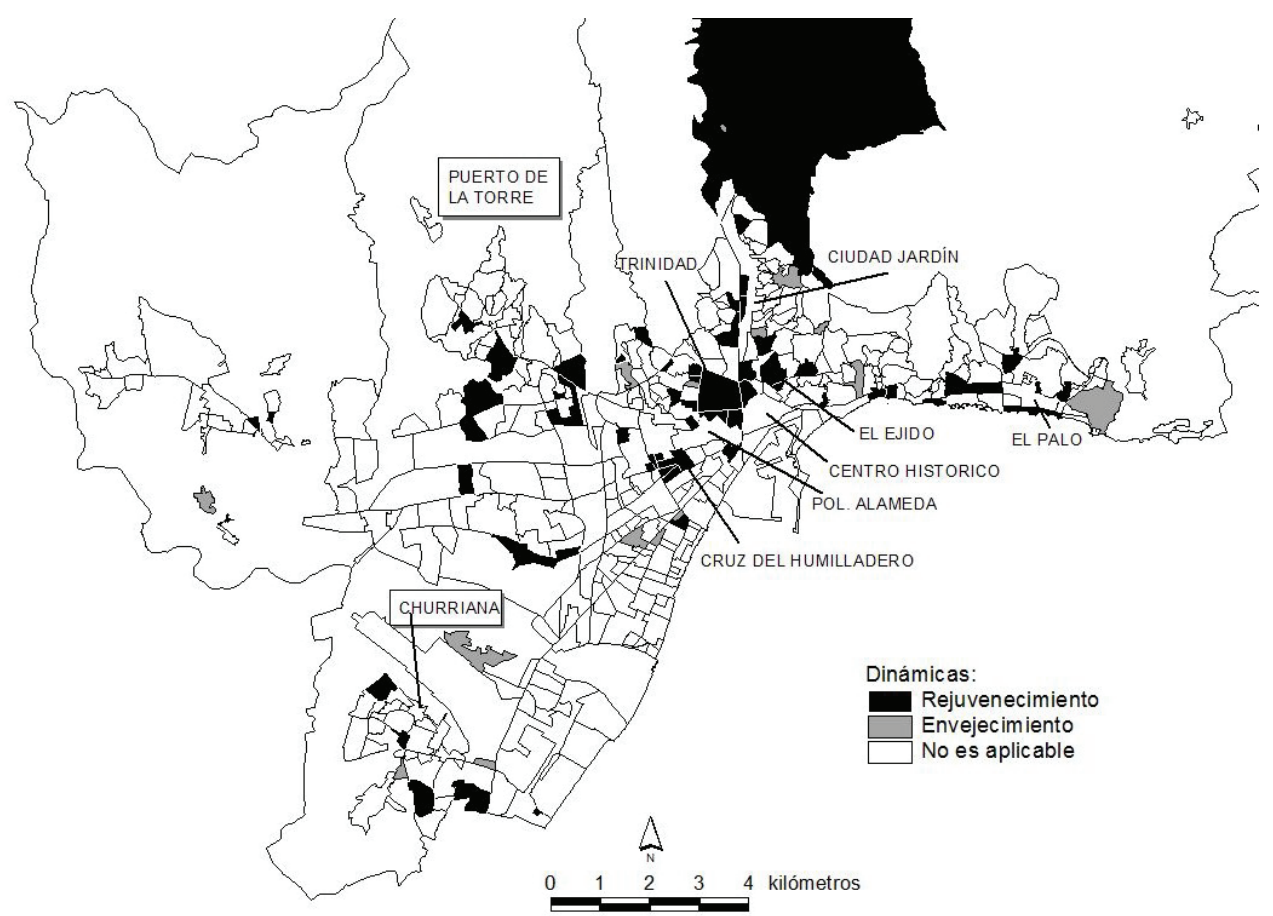

Fuente: Registros padronales a 1 de enero. Elaboración propia.

\section{CONCLUSIONES}

La llegada de inmigrantes al municipio de Málaga ha sido la responsable del crecimiento del total de población que la capital malacitana ha experimentado en los últimos años, y ha supuesto la multiplicación por 10 de la tasa de extranjería comparándola con la de 1998. Sin embargo, esta población no se ha asentado de manera uniforme en el tejido urbano, puesto que si bien es cierto que prácticamente la totalidad de los barrios malagueños cuentan con algún extranjero empadronado en ellos, también lo es el que el grueso de los mismos se concentran en el centro y sus aledaños, así como también en el entorno de núcleos tradicionales del municipio, unidos en la actualidad por coalescencia con el principal. Una localización mayoritaria que guarda gran relación la disponibilidad de vivienda, por lo general en alquileres a precios asequibles, dada la condición de inmigrante económico que caracteriza a una porción considerable de los foráneos empadronados en el municipio.

La disponibilidad de vivienda vacía en un barrio se incrementa cuando la población preexistente -mayoritariamente española- lo abandona, resultando de la combi- 
nación de la salida de españoles y de la paralela llegada de foráneos (atraídos por la posibilidad de encontrar una residencia) un proceso de sustitución de población, que puede estar enmarcado en una dinámica de pérdidas globales de población, cuando las llegadas no bastan para compensar las salidas, o ganancias netas, en caso contrario. En nuestro municipio, este proceso de sustitución de población está presente fundamentalmente en los barrios localizados en las porciones septentrional y occidental del continuo construido, siendo escasos los ejemplos en el oriente capitalino, debido básicamente a las condiciones diferenciales de la vivienda en esta zona.

En lo relativo al impacto de la población extranjera sobre la estructura por edad, debemos diferenciar dos niveles. El primero es el relativo al impacto sobre la población municipal tomada como un conjunto, impacto prácticamente inexistente, dada la escasa proporción que este segmento de empadronados supone sobre el total de la población empadronada en la capital. Pero cuando descendemos al nivel del barrio, este impacto es más marcado, más de lo que en principio podría suponerse dado el comparativamente pequeño número de extranjeros empadronados: la llegada de estos contingentes ha influido en la estructura por edad de 72 barrios (el 22\% de los considerados), y ha sido una influencia que ha derivado en el rejuvenecimiento de la población residente en la inmensa mayoría de los casos.

Hallazgos todos que, en nuestra opinión, no hacen sino remarcar la importancia de llevar a cabo estudios de esta naturaleza a un nivel de resolución espacial inferior al municipal, dado que a través de ellos pueden identificarse tendencias y situaciones que quedan enmascaradas al trabajar con las cifras agregadas, pudiéndose resolver, además, como instrumentos de apoyo en las políticas de gestión municipal.

\section{BIBLIOGRAFÍA}

ARBACI, S. (2007): Ethnic segregation, housing Systems and welfare regimes in Europe. European Journal o Housing Policy, 7, 4. 401-433.

BAYONA I CARRASCO, J. (2008): El impacto de la inmigración extranjera en la estructura demográfica de las ciudades. El caso de la ciudad de Barcelona y su área metropolitana. Arquitectura, Ciudad y Entorno, 3, 8, 119-142.

BAYONA I CARRASCO, J., y GIL ALONSO, F. (2008): El papel de la inmigración extranjera en la expansión de las áreas urbanas. El caso de Barcelona (1998-2007). Scripta Nova. Revista Electrónica de Geografía y Ciencias Sociales. Barcelona: Universidad de Barcelona, 1 de agosto de 2008, vol. XII, núm. 270 (161). <http:// www.ub.es/geocrit/sn/sn-270-161.htm> [ISSN: 1138-9788]

BAYONA I CARRASCO, J., y GIL ALONSO, F. (2010): Migraciones de españoles y extranjeros en las áreas rurales catalanas (1996-2006). ¿Fin de la despoblación o nuevo modelo territorial? Boletín de la Asociación de Geógrafos Españoles, 53, 219-237.

CARVAJAL GUTIÉRREZ, C. (2003): La presencia relativa de extranjeros en la provincia de Málaga según el Censo de 2001. Papeles de Geografía, 37, 27-39. 
CARVAJAL GUTIÉRREZ, C. (2005): Incidencia de los extranjeros en la estructura por edad de los municipios de Málaga. Cuadernos Geográficos, 36. 185-198.

GIL ALONSO, F. (2008): Una población en transformación: el impaco de la inmigración extranjera en las estructuras demográficas de la provincia de Barcelona (2000-2005). Treballs de la Societat Catalana de Geografia, 66, 151-172.

GONZÁLEZ RODRÍGUEZ, L. (2005): El impacto sociodemográfico de la inmigración extranjera en Vic (Osona, Cataluña, España). Cuadernos Geográficos, 36, 451-463.

KEMPEN, R. VAN, y ÖZÜEKREN, S. (1998): Ethnic segregation in cities: new forms and explanations in a dynamic world. Urban Studies, 35, 10, 1631-1656.

Fullaondo, A. (2007): La inmigración en España: una aproximación metropolitana comparada. Arquitectura, ciudad y entorno, 2, 4, 497-518.

HAFFAR LÓPEZ, L., y HEREDIA LACLAUSTRA, A. (2005): Las repercusiones de los movimientos migratorios en la estructura demográfica de la población aragonesa. Cuadernos Geográficos, 36, 319-332.

HUETE GARCÍA, Ma A., y MUÑOZ MORENO, R. (2010): "Modelos de barrio y lógicas de localización de la población inmigrante. El caso de la ciudad de Sevilla. Scripta Nova. Revista Electrónica de Geografía y Ciencias Sociales. [En línea]. Barcelona: Universidad de Barcelona, 20 de agosto de 2011, vol. XV, nº 372. $<$ http://www.ub.es/geocrit/sn/sn-372.htm>. [ISSN: 1138-9788].

LAVIIA MARTÍNEZ, C. (2008): "La segregación residencial de la población extranjera en Bilbao". Arquitectura, ciudad y entorno, 3, 8, 65-93.

LEAL MALDONADO, J. (2007): Cambios en la morfología social de las grandes ciudades españolas: apuntes para una investigación. Arquitectura, ciudad y entorno, 1, 3, 153-162.

LÓPEZ DE LERA, D., e IZQUIERDO ESCOLANO, A. (2003): La huella demográfica de la población extranjera en España. Sistema: revista de ciencias sociales, 175-176, 181-200.

LÓPEZ DE LERA, D., e IZQUIERDO ESCOLANO, A. (2005): Demografía de los extranjeros en Galicia: incidencia en el crecimiento de la población. Revista gallega de empleo, 4, 21-58.

MARTÍNEZ VEIGA, U. (1999): Pobreza, segregación y exclusión espacial. La vivienda de los inmigrantes extranjeros en España. Barcelona. Icaria.

OCAÑA OCAÑA, C. (1988): Estructuras sociodemográficas y áreas sociales en la ciudad de Málaga. Sevilla. Consejería de Obras Públicas y Transportes, Junta de Andalucía.

OCAÑA OCAÑA, C. (2005a). Microanálisis sociodemográfico de espacios urbanos. Boletín de la AGE, 40, 5-34.

OCAÑA OCAÑA, C. (2005b): Población y crecimiento urbano: Málaga, a comienzos del S.XXI. Málaga. Fundación CIEDES. 
OCAÑA OCAÑA, C. (2008): Urbanización y vivienda. Negocio financiero y conflicto social. Málaga. Colegio Oficial de Arquitectos de Málaga.

ROQUER, S., y BLAY, R. (2008): Del éxodo rural a la inmigración extranjera: el papel de la población extranjera en la recuperación demográfica de las zonas rurales españolas (1996-2006). Scripta Nova, Vol XII, No 279 (129), 1 de agosto de 2008. http://www.ub.edu/geocrit/sn/sn-270/sn-270-129.htm 